\title{
Pechini Synthesis and Microstructure of Nickel-Doped Copper Chromites
}

\author{
Patrícia Mendonça Pimentel, Antonio Eduardo Martinelli*, Dulce Maria de Araújo Melo, \\ Anne Michelle Garrido Pedrosa, Jardel Dantas Cunha, Carlos Neco da Silva Júnior \\ Universidade Federal do Rio Grande do Norte, Departamento de Química, \\ Laboratório de Análise Térmica e Materiais, C.P. 1662, 59078-970 Natal - RN, Brazil
}

Received: November 23, 2003; Revised: March 19, 2005

\begin{abstract}
Spinel-type solid solutions were synthesized by the Pechini method and calcined between 500 and $900{ }^{\circ} \mathrm{C}$ for 4 hours and at $900{ }^{\circ} \mathrm{C}$ for 8 hours to produce ceramic pigments. The resulting powders were characterized by thermogravimetric analysis, Fourier-transform infrared spectroscopy (FTIR), X-ray diffraction (XRD), scanning electron microscopy (SEM), particle size analysis and BET surface area measurements. The formation of spinel took place upon calcination at $700{ }^{\circ} \mathrm{C}$. IR spectroscopy revealed the presence of $v_{1}$ and $v_{2}$ bands, typical of spinel structures, broadened by the presence of more than one cationic species in the structure. The specific area of the resulting powder decreased from 24.7 to $1.4 \mathrm{~m}^{2} \mathrm{~g}^{-1}$ as the calcination temperature increased from 700 to $900{ }^{\circ} \mathrm{C}$. Microstructural analyses revealed the presence of crystalline spinel as the only phase present in powders calcined at $900{ }^{\circ} \mathrm{C}$. Colorimetric analyses using $\mathrm{L} * \mathrm{a} * \mathrm{~b} *$ coordinates and UV-visible spectroscopy revealed that the pigment was predominantly black.
\end{abstract}

Keywords: spinel, chromites, Pechini method, ceramic pigments

\section{Introduction}

Spinels are ternary oxides with the general formula $\mathrm{AB}_{2} \mathrm{O}_{4}$, where $\mathrm{A}$ and $\mathrm{B}$ are cations occupying tetrahedral and octahedral sites respectively. These oxides exhibit interesting electric, magnetic and catalytic properties ${ }^{1-4}$, depending on their nature, charge, and distribution of ions at interstices ${ }^{5}$. $\mathrm{CuCr}_{2} \mathrm{O}_{4}$ crystallizes as a tetragonally distorted spinel structure. Its distortion is related to the cooperative Jahn-Teller effect of $\mathrm{Cu}^{2+}$ at the tetrahedral sites ${ }^{6}$. The substitution of tetrahedral $\mathrm{Cu}^{2+}$ ions by any bivalent cation does not affect the distribution of cations in the substituted spinel oxides ${ }^{7,8}$. Site preference energies for oxide spinels indicate that $\mathrm{Ni}^{2+}$ and $\mathrm{Cr}^{3+}$ occupy octahedral sites, although $\mathrm{Cr}^{3+}$ is also capable of forcing $\mathrm{Ni}^{2+}$ into tetrahedral positions ${ }^{7}$.

The most widely used method for the preparation of spinels involves solid-state reaction of mechanically mixed metal oxides at high temperatures ${ }^{9,10}$. The Pechini method ${ }^{11,12}$, based on polymeric precursors, can be used to prepare spinels and it does not require high temperature calcinations and permits good stoichiometric control as well as reproducibility. This method consists of the formation of a polymeric resin between a metallic acid chelate and polyhydroxide alcohol by polyesterification.

This study is focused on the preparation of solid solutions of copper chromites doped with nickel by the Pechini method, and the investigation of the effect of heat treatment on particle size and morphology. X-ray diffraction (XRD) and Fourier Transform Infrared Spectroscopy (FTIR) patterns were used to reveal the structural properties of the materials formed.

\section{Experimental}

\subsection{Synthesis}

Nickel-doped copper chromite powders were prepared from polymeric precursors by the Pechini method. The metal nitrate solution was mixed with a stoichiometric amount of citric acid. The resulting solution was stirred for about 1 hour on a hot plate and the temperature was stabilized at $70{ }^{\circ} \mathrm{C}$. The mixture was heated to $90{ }^{\circ} \mathrm{C}$, at which point ethylene glycol was added at a mass ratio of 40:60 with respect to citric acid. The temperature was maintained constant up to resin formation, which polymerized at $300{ }^{\circ} \mathrm{C}$. The precursor powders were then calcined for 4 hours at various temperatures, ranging from 500 to $900{ }^{\circ} \mathrm{C}$, or at $900{ }^{\circ} \mathrm{C}$ for 8 hours.

\subsection{Characterization}

Chemical analyses of the metallic constituents were carried out by atomic absorption spectroscopy and a Spectra 110 Varian setup was used. Thermogravimetric analyses of the polymeric precursors were carried out in a TGA-7 Perkin Elmer balance by heating samples of $2.15 \mathrm{mg}$ at $5{ }^{\circ} \mathrm{C} \mathrm{min}-1$ in flowing air $\left(50 \mathrm{~mL} \mathrm{~min}^{-1}\right)$. Particle size distributions were obtained in a CILAS 1064 laser analyzer. Infrared spectra (FTIR) were recorded using $\mathrm{KBr}$ pellets in a Perkin-Elmer $16 \mathrm{PC}$ instrument. X-ray diffraction patterns (XRD) were obtained from a Shimadzu XRD-6000 X-ray difractometer using $\mathrm{CuK} \alpha$ radiation $(\lambda=1.5418 \AA)$. The specific surface area of the powders was measured by nitrogen adsorption on a NOVA 2000 BET system. The microstructure of the powders was observed by examining Au-coated samples in a Philips ESEM-XL30 scanning electron microscope that was set in the high-vacuum mode. The diffuse reflectance of the powders was measured in the 300-800 nm range using a Gretac Macbeth 2180-2180 UV spectrophotometer (D-65 light). The color of the pigment was evaluated from $\mathrm{L}^{*} \mathrm{a} * \mathrm{~b} *$ colorimetric coordinates according to CIE (Commission Internationale I'Eclairage) standards using

$$
\Delta E^{2}=L^{2}+a^{2}+b^{2}
$$

where $\mathrm{L}^{*}$ varies from black (0) to white (100), $\mathrm{a}^{*}$ from green (-) to red $(+)$, and $b^{*}$ from blue (-) to yellow (+).

\section{Results and Discussion}

The stages of decomposition of the polymeric precursor to form $\mathrm{Cu}_{0.8} \mathrm{Ni}_{0.2} \mathrm{Cr}_{2} \mathrm{O}_{4}$ spinel were revealed in the thermogravimetric analysis (Figure 1). Initially, thermal decomposition of the mixture took place at about $30{ }^{\circ} \mathrm{C}$ with onset of decomposition of citric acid present in the polymerized solution. Following elimination of residual water, 
the material lost $2 \%$ of its mass upon heating to $500{ }^{\circ} \mathrm{C}$, due to decomposition of organic compounds. Samples calcined from 500 to $900{ }^{\circ} \mathrm{C}$ revealed no additional mass loss.

$\mathrm{X}$-ray diffraction patterns of the calcined powders are shown in Figure 2. The presence of a distorted tetragonal spinel phase along with other crystalline phases, such as $\mathrm{CuO}$ and $\mathrm{Cr}_{2} \mathrm{O}_{4}$, could be observed. Although spinel was formed even at relatively low calcining temperatures, it is possible to observe the steady increase in the

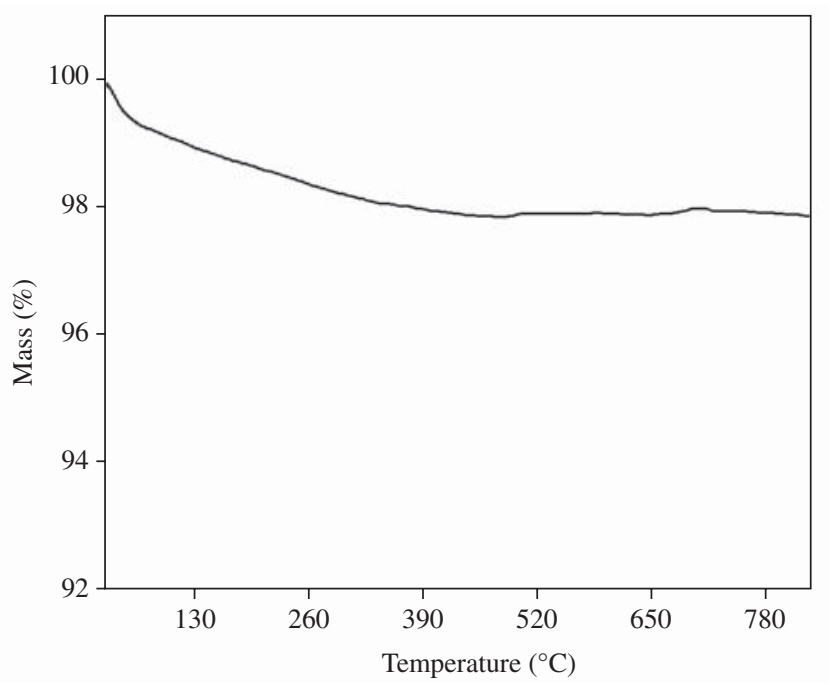

Figure 1. Thermogravimetric plot of the spinel polymeric precursor.

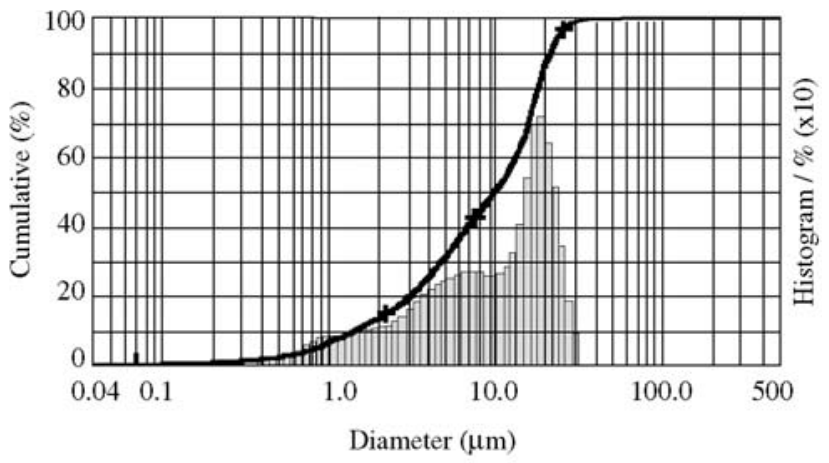

(a)

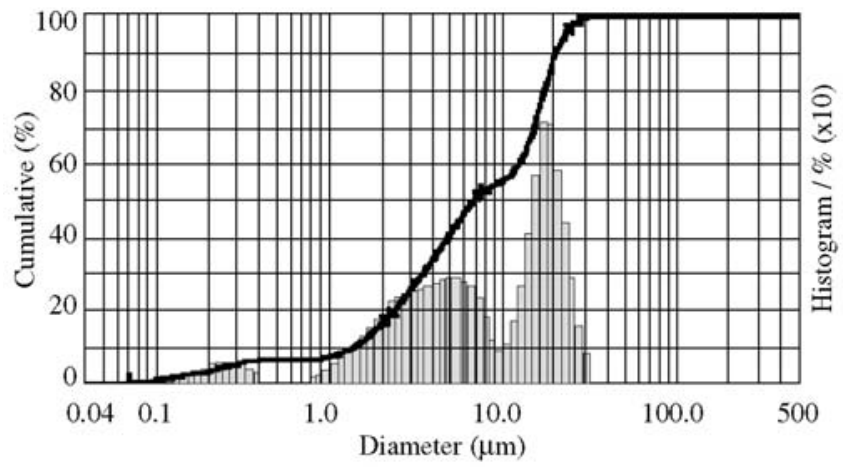

(c) relative peak intensity of spinel with respect to $\mathrm{CuO}$ and $\mathrm{Cr}_{2} \mathrm{O}_{4}$, with increasing synthesis temperature. This indicated ongoing crystallization of spinel from its precursors. The synthesis of spinel also affected particle size distribution in the resulting powder (Figure 3). Although slight, it is possible to notice that the average particle size (D50) of the powder, representative of powder agglomerates, steadily decreased from $\sim 10 \mu \mathrm{m}$ to $\sim 6 \mu \mathrm{m}$ as the calcining temperature increased from 500 to $900{ }^{\circ} \mathrm{C}$ and time from 4 to 8 hours at $900{ }^{\circ} \mathrm{C}$. In addition, the

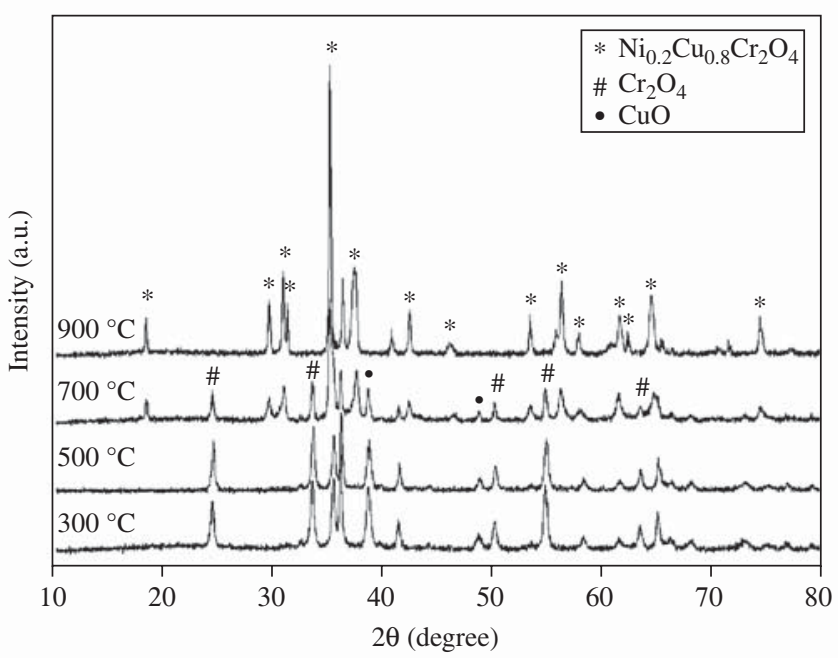

Figure 2. X-ray diffraction patterns of the polymeric precursor and powders calcined at $500{ }^{\circ} \mathrm{C}, 700{ }^{\circ} \mathrm{C}$, and $900{ }^{\circ} \mathrm{C}$ for 4 hours.

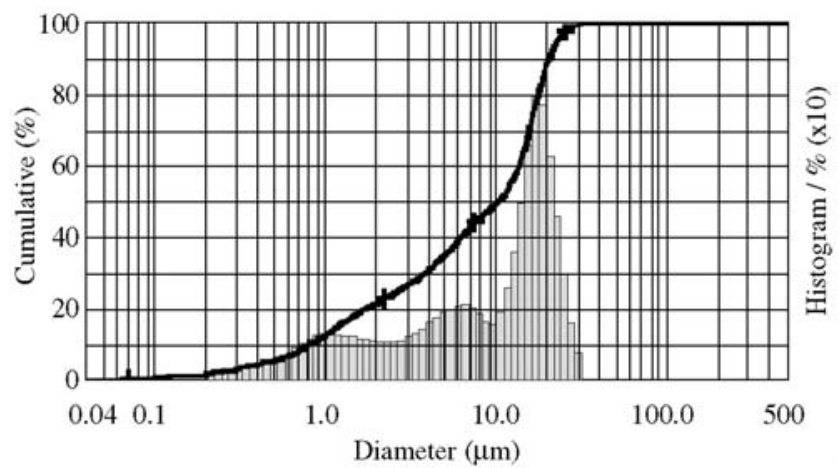

(b)

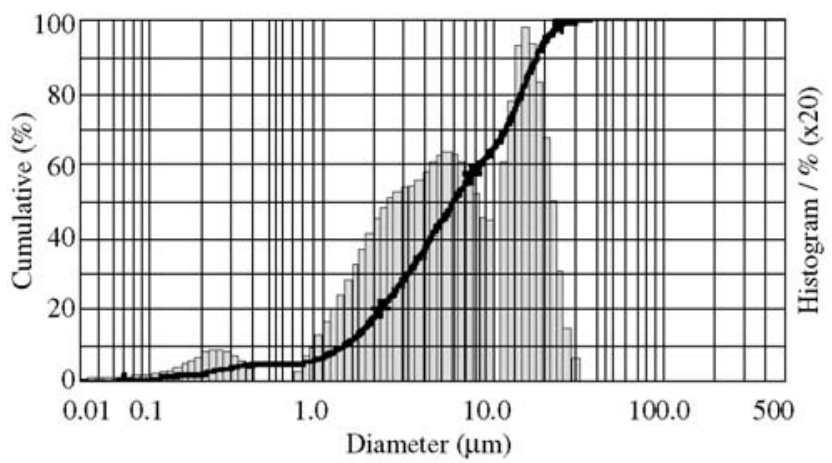

(d)

Figure 3. Particle size distribution of powders calcined at: a) $500{ }^{\circ} \mathrm{C}$; b) $700{ }^{\circ} \mathrm{C}$; c) $900{ }^{\circ} \mathrm{C}$ for 4 hours; d) $900{ }^{\circ} \mathrm{C}$ for 8 hours. 
fraction of fine loose particles (equivalent diameter $<1 \mu \mathrm{m}$ ) also increased with crystallization of spinel. This can be confirmed from the SEM images shown in Figure 4. Along with changes in particle morphology as a function of calcining temperature, heat treatment at $500{ }^{\circ} \mathrm{C}$ (Figure 4a) resulted in substantial agglomeration of the powder, which is typical of the presence of unreacted $\mathrm{CuO}$ and $\mathrm{Cr}_{2} \mathrm{O}_{4}$. Calcining at higher temperatures $\left(700\right.$ or $\left.900{ }^{\circ} \mathrm{C}\right)$ or longer times ( 8 hours) resulted in loose and fine octahedron-shaped crystals characteristic of spinel and agglomerates. The values summarized in Table 1 reveal that the formation of spinel was accompanied by a steady decrease in specific surface area, a consequence of consumption of $\mathrm{CuO}-\mathrm{Cr}_{2} \mathrm{O}_{4}$ irregular agglomerates to form regular-shaped spinel nanocrystals. The relatively low values encountered are typical of Pechini synthesis, and can be attributed to the M:AC (M = Metal; $\mathrm{AC}=$ citric acid) molar ratio used in the synthesis, and consequently, to the chain polymer size used in pigment preparation.

According to group theory, spinel type oxides should exhibit four IR bands $v_{1}-v_{4}^{13-14}$. In this investigation measurements were carried out up to $500 \mathrm{~cm}^{-1}$, thus limiting the study to the high frequency bands $\left(v_{1}\right.$ and $v_{2}$ ) of the IR spectrum. Since these bands are nearly insensitive to changes in the bivalent cation ${ }^{9}$, they should not be significantly affected when $\mathrm{Cu}^{2+}$ from $\mathrm{CuCr}_{2} \mathrm{O}_{4}$ is substituted by another bivalent cation. The infrared spectra are shown in Figure 5. Both, $v_{1}$ at $665 \mathrm{~cm}^{-1}$, and $v_{2}$ at $580 \mathrm{~cm}^{-1}$ are related to bonds of the internal tetrahedra and octahedra

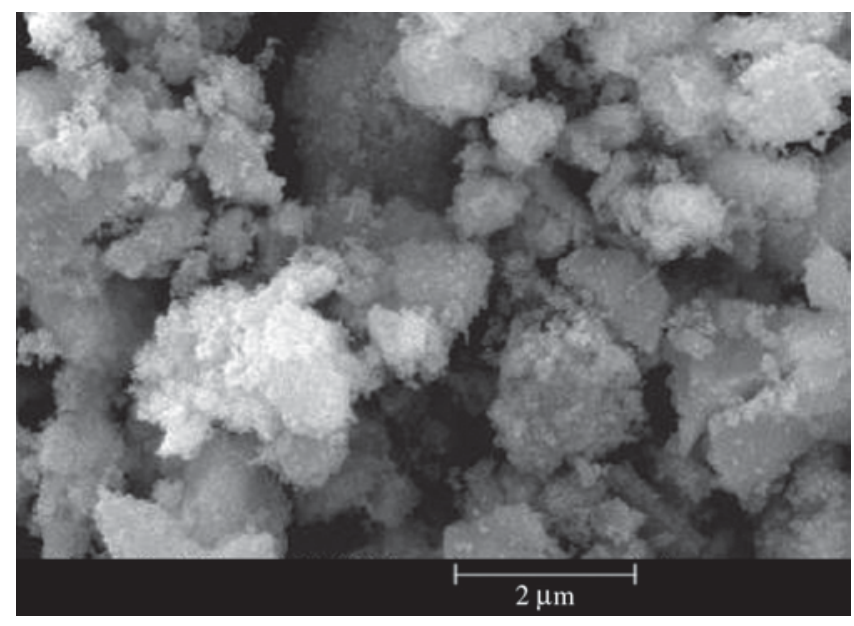

(a)

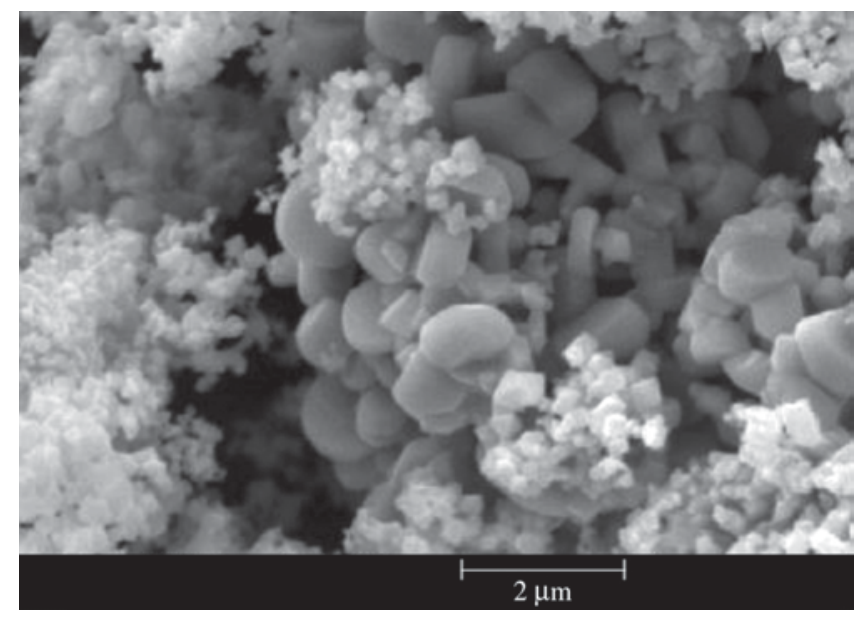

(c) of the structure of $\mathrm{Cu}_{0.8} \mathrm{Ni}_{0.2} \mathrm{Cr}_{2} \mathrm{O}_{4}$. The broadening of these bands is probably due to the presence of more than one type of cation ${ }^{14}$.

Results from UV- visible spectroscopy (Figure 6) revealed an absorption band in the 400-700 $\mathrm{nm}$ range as a result of complete light absorption, typical of highly reflective systems. This was further confirmed by the colorimetric coordinates (Table 2). The relatively high values of $\mathrm{L}^{*}$ (31.81) along with low $\mathrm{a}^{*}$ and $\mathrm{b}^{*}, 0.10$ and 1.07 respectively, suggested full light absorption, and consequently a black pigment. When applied to ceramic frits the pigment remained

Table 1. Specific surface area of calcined powders.

Calcination profile

$500{ }^{\circ} \mathrm{C} / 4 \mathrm{~h} \quad 700{ }^{\circ} \mathrm{C} / 4 \mathrm{~h} \quad 900{ }^{\circ} \mathrm{C} / 4 \mathrm{~h} \quad 900{ }^{\circ} \mathrm{C} / 8 \mathrm{~h}$

\begin{tabular}{|c|c|c|c|c|}
\hline $\begin{array}{l}\text { Specific } \\
\text { surface area } \\
\left(\mathrm{m}^{2} \mathrm{~g}^{-1}\right)\end{array}$ & 24.7 & 7.2 & 2.0 & 1.4 \\
\hline
\end{tabular}

Table 2. Colorimetric coordinates of powder calcined at $900{ }^{\circ} \mathrm{C}$ for 8 hours.

\begin{tabular}{lrcc}
\hline & $\mathrm{L}^{*}$ & $\mathrm{a}^{*}$ & $\mathrm{~b}^{*}$ \\
\hline Powder & 31.81 & 0.10 & 1.07 \\
Frit & 0.00 & 0.00 & 0.00 \\
\hline
\end{tabular}

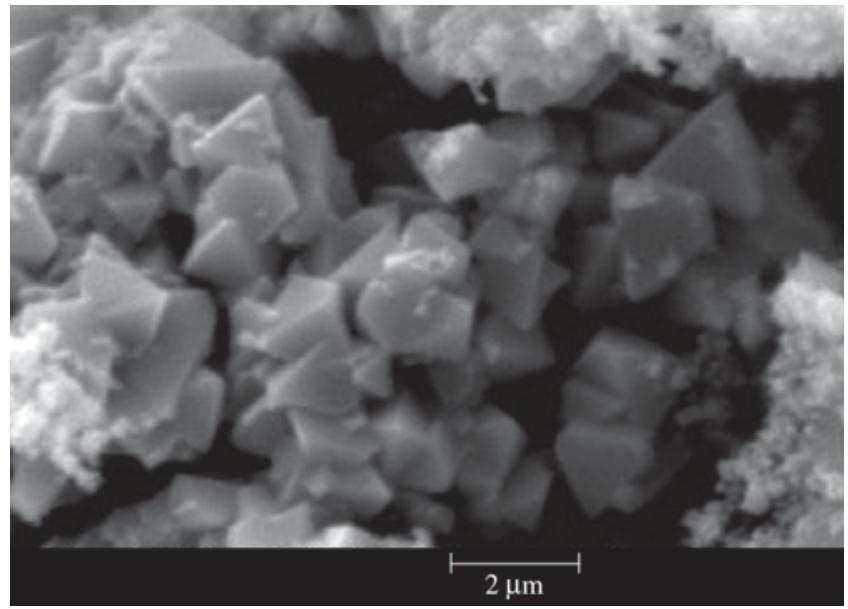

(b)

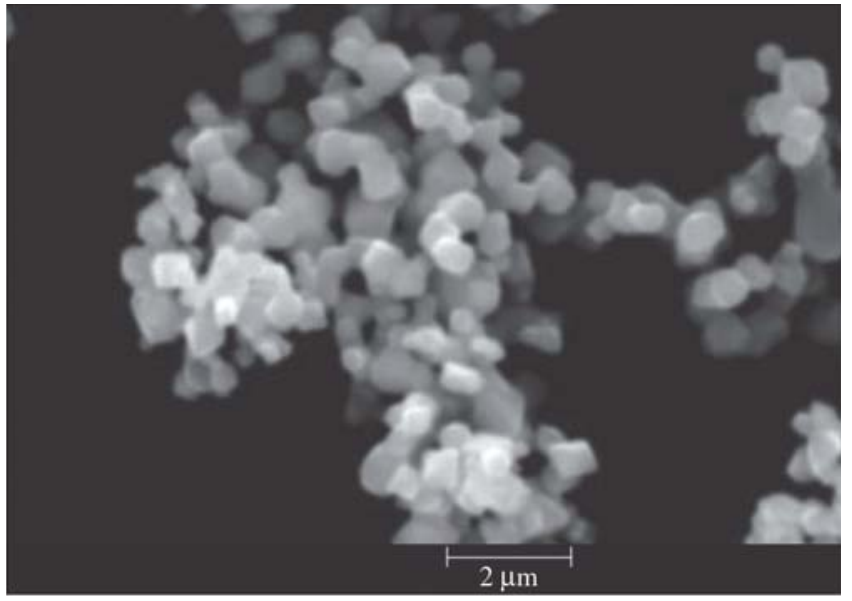

(d)

Figure 4. SEM images of powders calcined at: a) $500{ }^{\circ} \mathrm{C}$; b) $700{ }^{\circ} \mathrm{C}$; c) $900{ }^{\circ} \mathrm{C}$ for 4 hours; d) $900{ }^{\circ} \mathrm{C}$ for 8 hours. 


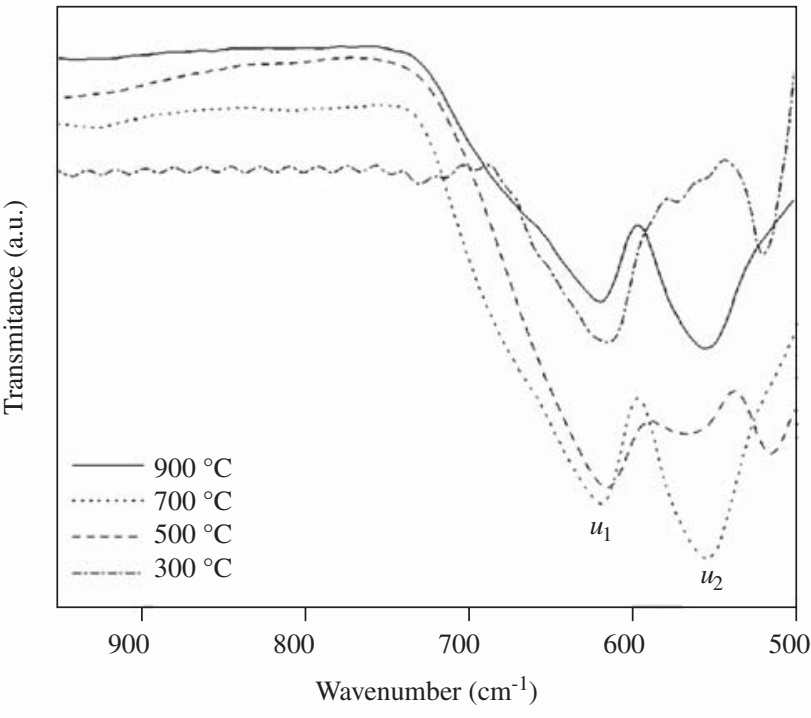

Figure 5. Infrared absorption pattern of the polymeric precursor and powders calcined at $500{ }^{\circ} \mathrm{C}, 700{ }^{\circ} \mathrm{C}$, and $900^{\circ} \mathrm{C}$ for 4 hours.

black although it changed its hue slightly. The values $\mathrm{L}^{*}, \mathrm{a}^{*}$ and $\mathrm{b}^{*}$ changed to zero as a consequence of the interaction of the pigment with the glassy material.

\section{Conclusions}

$\mathrm{Cu}_{0.8} \mathrm{Ni}_{0.2} \mathrm{Cr}_{2} \mathrm{O}_{4}$ spinel was synthesized from polymeric precursors using the Pechini method. The crystallization of the spinel structure upon calcining at $700{ }^{\circ} \mathrm{C} . \mathrm{Cu}_{0.8} \mathrm{Ni}_{0.2} \mathrm{Cr}_{2} \mathrm{O}_{4}$ was the only phase present upon calcination at $900{ }^{\circ} \mathrm{C}$. Both, loose particles and agglomerates were formed. The average size of the powder was $8 \mu \mathrm{m}$. Black pigments were obtained from the synthesis. Despite slight variations in the colorimetric coordinates, no significant change in color was observed when the pigments were applied to ceramic frits.

\section{Acknowledgments}

The authors would like to thank CNPq as well as the National Petroleum Agency (ANP-Brazil) for providing the financial support necessary to carry on the present research work through its Human Resource Program PRH-30-UFRN.

\section{References}

1. Nathawan P, Darshane VS. Structural. Transport, magnetic and infrared studies of the oxidic spinels $\mathrm{Co}_{2-\mathrm{X}} \mathrm{Ti}_{1-\mathrm{X}} \mathrm{Fe}_{2 \mathrm{X}} \mathrm{O}_{4}$. Journal of Physics. 1988; 21(6):3191-3203.

2. Vlasenko VM, Chernobrivets VL. Methane chlorination on spinel copperchromium catalyst in the presence of oxygen. Russian Journal of Applies Chemistry. 1998; 71(8):1393-1396.

3. Erran E, Trifino F, Vaccari A, Richter M. Structure and reactivity of Zn$\mathrm{Cr}$ mixed oxides Role of non-stoichiometry in the catalytic synthesis of methanol. Catalysis Letter. 1989; 3(1):65-72.

4. Câmara MSC, Lisboa-Filho PN, Cabrelon MD, Gama L, Ortiz WA, Paiva-

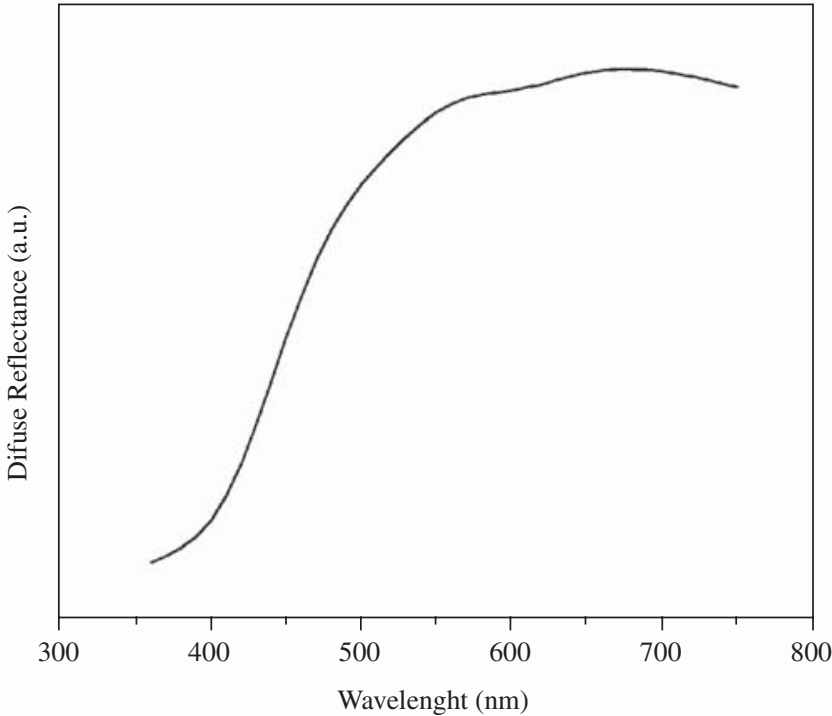

Figure 6. UV-Visible pattern of nickel-doped copper chromites calcined at $900{ }^{\circ} \mathrm{C}$ for 8 hours.

Santos CO, Leite ER, et al. Synthesis and characterization of $\mathrm{Li}_{2} \mathrm{ZnTi}_{3} \mathrm{O}_{8}$ spinel using the modified polymeric precursor method. Materials Chemistry and Physics. 2003; 82(1):68-72.

5. McClure D. The distribution of transition metal action in spinels. Journal of Physical Chemistry Solids. 1957; 3:311-317.

6. Roy S, Ghose J. Synthesis and studies on some cooper chromite spinel oxide composites. Materials Research Bulletin. 1999; 34(7):1179-1186.

7. Jendrzejewska I. Influence of nickel substitution on the crystal structure of $\mathrm{CuCr}_{2} \mathrm{Se}_{4}$. Journal of Alloys Compounds. 2000; 305(1):90-92.

8. Okonska Kozlowska I, Kopyczok J, Lutz HD, Stingl TH. Single-crystal structure refinement os spinel-type $\mathrm{CuCr}_{2} \mathrm{Se}_{4}$. Acta Crystallographica Section C - Crystal Structure Communications. 1993; 49(8):1448-1449.

9. Preudhomme J, Tarte P. Infrared studies of spinels-III. The normal II-III spinels. Spectrochimica Acta Part A: Molecular Spectroscopy. 1971; 27(90):1817-1835.

10. Chokkaram S, Srinivasan R, Milbrun DR, Davis BH, Conversion of 2-octanol over nickel-alumina, cobalt-alumina, and alumina catalysts. Journal of Molecular Catalysis A: Chemical. 1997; 121(2-3):157-169.

11. Pechini M P. US Patent. 3330697, 1967.

12. Lessing PA Mixed-cation powders via polymeric precursors. American Society Ceramic Bulletin. 1989; 68(5):1002-1007.

13. Lutz HD, Waschenbach G, Khiche G, Hacuseler H. Latice vibrationspectra .33. far-infrared reflection spectra, to and lo phonon frequencies, optical and dielectric-constants, and effective charges of the spinel-type compounds $\mathrm{MnCr} 254$, FeCr254, CoCr254, ZnCr254, CdCr254, $\mathrm{HgCr} 254$, ZnCr25E4, CdCr25E4, HgCr25E4, MnIn254, FeIn254, CoIn254, NiIn254, CdIn254, HgIn254. Journal of Solid State Chemistry. 1983; 48(2):196-208.

14. Basak D, Ghose J. Infrared studies on some substituted copper chromite spinels. Spectrochimica Acta Part A: Molecular Spectroscopy. 1994; 50(4):713-718. 